\title{
Epidemiological, Etiological, Therapeutic and Evolutionary Aspects of Acute Surgical Abdomens Operated at the University Hospital of Bobo-Dioulasso
}

\author{
Cyprien Zaré ${ }^{1 *}$, Hermann Belemlilga ${ }^{1}$, Edgard Ouangre ${ }^{2}$, Maurice Zida² ${ }^{2}$ Bakary Gustave Sanon1,

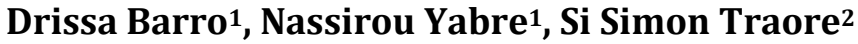

${ }^{1}$ Department of General and Digestive Surgery of the University Hospital Center Souro Sanou, Bobo-Dioulasso, Burkina Faso

${ }^{2}$ Service of General and Visceral Surgery CHUYO, Ouagadougou, Burkina Faso

Email: *zcyprien@yahoo.fr

How to cite this paper: Zaré, C., Belemlilga, H., Ouangre, E., Zida, M., Sanon, B.G., Barro, D., Yabre, N. and Traore, S.S. (2018) Epidemiological, Etiological, Therapeutic and Evolutionary Aspects of Acute Surgical Abdomens Operated at the University Hospital of Bobo-Dioulasso. Surgical Science, 9, $1-7$.

https://doi.org/10.4236/ss.2018.91001

Received: November 12, 2017

Accepted: December 31, 2017

Published: January 3, 2018

Copyright $\odot 2018$ by authors and Scientific Research Publishing Inc. This work is licensed under the Creative Commons Attribution International License (CC BY 4.0).

http://creativecommons.org/licenses/by/4.0/

\begin{abstract}
Surgical acute abdomens represent a significant proportion of surgical emergencies in terms of frequency, morbidity and mortality. The aim of our study was to describe the epidemiological, diagnostic, therapeutic and evolutionary aspects of acute surgical abdomens operated in the surgical emergency department of the Centre Hospitalier Universitaire Souro Sanou (CHUSS). This was a retrospective descriptive study of 426 cases of surgical acute abdomens operated in the CHUSS surgical emergency department from 1 January to 31 December 2015. These 426 cases accounted for $24.14 \%$ of the emergency interventions carried out in the CHUSS surgical emergency department. These were $314(73.7 \%)$ men and $112(26.3 \%)$ women with an average age of 30 years. Among the causes, there were 187 (43.9\%) cases of acute generalized peritonitis, $71(16.7 \%)$ cases of acute intestinal occlusions, 49 (11.5\%) cases of acute appendicitis, $38(9.4 \%)$ cases of strangulated parietal hernias, $16(3.8 \%)$ cases of abdominal contusions, and $15(3.5 \%)$ cases of penetrating wounds of the abdomen. The appendectomy was the most performed gesture with 112 (26.3\%) cases. The time to surgery was greater than 48 hours in $29(6.8 \%)$ cases. Complications were observed in $68(16 \%)$ cases with $35(8.2 \%)$ cases of parietal infections, 18 (4.2\%) cases of postoperative peritonitis. The death occurred in 37 (8.7\%) patients. The average hospital stay was 8.7 days. Improving the prognosis of acute surgical abdomens requires early diagnosis and treatment, as well as better postoperative follow-up.
\end{abstract}

\section{Keywords}

Surgical Emergencies, Abdomen, Bobo-Dioulasso 


\section{Introduction}

Henri Mondor defines surgical acute abdomens as being abdominal affections which, for the most part, due to a lack of surgical intervention obtained without delay, cause the patients to succumb in a few hours or a few days [1]. In the CHUSS, $82.3 \%$ of the interventions in general and digestive surgery are carried out in emergency. The majority of these interventions are performed for an acute surgical abdomen as in several other Sub-Saharan African countries. In Niger, Harouna found that acute surgical abdomens accounted for $62 \%$ of emergency interventions [2]. These emergencies are characterized by an important delay on consultation and surgical management. As consequence, mortality rate is important, counting from $17 \%$ to $33 \%$ [2] [3] [4]. Papers on acute surgical abdomens at the CHUSS are limited. The aim of our work was to describe the epidemiological, etiological, therapeutic and evolutionary aspects of surgical acute abdomens operated in the surgical emergency department of the CHUSS.

\section{Methodology}

The CHUSS surgical emergency department performs emergency surgery in general and digestive surgery, urology, orthopedics traumatology, neurosurgery, otolaryngology, odontostomatology. There were 5 surgeons in the general and digestive surgery department and 4 anesthesiologists in the multi-purpose intensive care unit.

This was a retrospective descriptive study of a year from January 1 to December 31, 2015. All patients admitted and operated for an acute surgical abdomen were included. Data were collected through a survey card gathering the information of the patient files (age, sex) and the registers of entries and exits of the surgical ward, operating theater, the intensive care unit. The survey card reported the admission delay (the period corresponding to the time elapsed between the beginning of the abdominal symptoms and the arrival of the patient in the emergency department), the surgical delay, the intraoperatory diagnosis, the surgical procedures carried out, postoperative course (morbidity and lethality) and length of stay. Data were collected, registered and analyzed using an Excel ${ }^{\circledR}$ sheet. Simple arithmetic operations permitted to obtain proportions and percentages. Results were presented in tables.

\section{Results}

We collected 426 cases of acute surgical abdomens operated in the CHUSS surgical emergency department, which accounted for $24.14 \%$ of emergency interventions. There were $314(73.7 \%)$ men and $112(26.3 \%)$ women, a sex ratio of 2.8. The average age was 30 years with extremes from 1 day to 78 years. These were non-traumatic abdomens in 395 (92.7\%) cases and traumatic in $31(7.3 \%)$ cases. Table 1 shows the different etiologies of non-traumatic abdomens. Of these, 187 (43.9\%) were cases of acute generalized peritonitis, 71 (16.7\%) acute intestinal occlusion, 49 (11.5\%) acute appendicitis, 38 (9.4\%) cases of strangulated 
Table 1. Non-traumatic etiologies of acute surgical abdomens.

\begin{tabular}{|c|c|c|}
\hline Non-traumatic etiologies & Cases & Percentages \\
\hline Acute generalized peritonitis & 187 & $43.9 \%$ \\
\hline Gastroduodenal perforated ulcer & 77 & $18.1 \%$ \\
\hline Typhoid perforation & 44 & $10.3 \%$ \\
\hline Appendicular peritonitis & 33 & $7.7 \%$ \\
\hline Primitive peritonitis & 10 & $2.3 \%$ \\
\hline Postoperative peritonitis & 2 & $0.5 \%$ \\
\hline Other & 22 & $5.2 \%$ \\
\hline Intestinal occlusion & 71 & $16.7 \%$ \\
\hline Flanges & 35 & $8.2 \%$ \\
\hline Volvulus & 20 & $4.7 \%$ \\
\hline Tumors & 3 & $0.7 \%$ \\
\hline Other & 13 & $3.1 \%$ \\
\hline Appendicitis & 49 & $11.5 \%$ \\
\hline Strangulated parietal hernia & 40 & $9.4 \%$ \\
\hline Inguinal & 30 & $7 \%$ \\
\hline Umbilical & 6 & $1.4 \%$ \\
\hline White line & 3 & $0.7 \%$ \\
\hline Crural & 1 & $0.2 \%$ \\
\hline Appendicular abscess & 16 & $3.8 \%$ \\
\hline Acute intestinal intussusception & 15 & $3.5 \%$ \\
\hline Neonatal surgical emergencies & 10 & $2.3 \%$ \\
\hline Other & 7 & $1.6 \%$ \\
\hline
\end{tabular}

Table 2. Traumatic etiologies of acute surgical abdomens and topography of lesions.

\begin{tabular}{ccc}
\hline Traumatic etiologies & Cases & Percentages \\
\hline Abdominal injuries & 16 & $3.8 \%$ \\
Intestine & 6 & $1.8 \%$ \\
Spleen & 4 & $0.9 \%$ \\
Liver & 3 & $0.7 \%$ \\
Stomach & 1 & $0.2 \%$ \\
Wall & 2 & $0.5 \%$ \\
Abdominal penetrating wounds & 15 & $3.5 \%$ \\
Intestine & 3 & $0.7 \%$ \\
Liver & 2 & $0.5 \%$ \\
Gallbladder & 1 & $0.2 \%$ \\
Wall & 9 & $2.1 \%$ \\
\hline
\end{tabular}

parietal hernias. Table 2 details the etiologies of the traumatic abdomens and the topography of the lesions. The abdominal contusions accounted for 16 (3.8\%) 
cases and penetrating wounds (3.5\%) cases.

The delay before surgery was less than 24 hours in 304 (71.4\%) cases, between 24 and 48 hours in $76(17.8 \%)$ cases, greater than 48 hours in $29(6.8 \%)$ cases. The surgical gestures performed were: 112 (26.3\%) appendectomies, $110(25.8 \%)$ digestive perforation sutures, 66 (15.3\%) intestinal anastomoses, and $49(11.5 \%$ $5 \%)$ hernia cures.

The evolution was marked by complications in 68 (16\%) cases. The complications were: $(8.2 \%)$ cases of parietal infection, $18(4.2 \%)$ cases of postoperative peritonitis, $5(1.2 \%)$ cases of fistula, $10(2.3 \%)$ evisceration.

The average hospital stay was 8.7 days with extremes of 0 to 95 days.

The death occurred in $37(8.7 \%)$ patients. The cause of death was acute generalized peritonitis in $16(43.24 \%)$ cases, acute intestinal occlusion in $10(27.2 \%)$ cases, acute intussusception in $3(8.1 \%)$ cases, parietal hernia in $2(5.4 \%)$ cases, neonatal emergencies in 2 cases (5.4\%), appendicular abscess in $1(2.7 \%)$ case.

\section{Discussion}

Surgical acute abdomens are frequent affections in African surgical environment. They accounted for one-quarter of emergency surgeries in our series. This result was lower than that reported by Harouna who accounted for $62 \%$ of emergency operating theaters [2]. Several African series confirm the important role played by digestive emergencies in surgical emergency activities [3]-[8]. Paradoxically, the management of these vital emergencies with severe prognosis is affected by the shortage of visceral surgeons and other qualified personnel. Thus the management of digestive emergencies is not optimal in our context, which explains why the surgical emergency services are the subject of strong criticism from the general public.

In our series acute surgical abdomens predominated in young adult male. This observation noted by several authors [2] [3] [4] [5] [6] [9] is explained by the youth of the population and the elective frequency of certain pathologies in this population. In fact, acute generalized peritonitis and acute intestinal occlusions, which are the most represented pathologies in our series, predominate in this segment of the population [10] [11] [12]. Moreover, as with other authors, we explain the male predominance by not including gynecological and obstetric emergencies that are taken care of in the specialty department [9] [13].

Acute generalized peritonitis was the first cause of surgical acute abdomens in our series, followed by acute intestinal occlusion, and acute appendicitis. Although there is a disparity in frequency, these three affections are the first three causes of acute surgical abdomens in several African studies [2] [3] [4] [5] [6] [9]. The etiological distribution of acute generalized peritonitis showed that gastric or duodenal ulcer perforation was the first etiology, followed by typhoidal ileal perforation and appendicular peritonitis. These three etiologies of peritonitis are commonly found but sometimes in a different frequency order [2] [6] [8] [9]. The incidence of acute peritonitis is due to typhoid fever endemic, insuffi- 
cient management of acute appendicitis and peptic ulcer disease.

As for strangulated hernia, acute intestinal intussusception, anorectal malformation, Hirschsprung's disease in acute intestinal occlusions. Thus, the heterogeneity of the classification of occlusions in the various studies [7] does not allow a comparison of the frequency and their etiologies with acute intestinal occlusions. We found as Soumah [9] in Senegal that brides and volvulus were the main etiologies. In our series, we had not classified there. The acute surgical abdomens were of traumatic origin in $7.3 \%$ of cases, with a similar frequency of bruises and sores of the abdomen. According to Harouna, abdominal trauma accounted for $9.3 \%$ of surgical digestive emergencies [2]. The development of transport means, with the consequent increase in traffic accidents, explains the frequency of trauma in the abdomen. Another cause of the trauma is beatings and wounds.

The average time between admission and surgery was long as it was more than 24 hours in $23.4 \%$ of cases. This delay was more pronounced in the Rasamoelina series [14] in Madagascar, which had an average treatment time of 32 hours with $70.6 \%$ of patients treated after 24 hours. Harouna [2] noted an average of 3 hours that is acceptable for surgical emergencies. Surgical acute abdomens should be cared for within a more or less short time according to the degree of urgency classified in relative, absolute, or extreme urgency. The management of emergencies in our context faces the shortage of qualified personnel, infrastructure, equipment, a system of mutual social assistance (health insurance, mutual health...) little developed. The prognosis of surgical acute abdomens is thus aggravated by the lengthening of treatment delays.

The most performed surgical procedure was the appendectomy followed by the stoma. Harissou [7] found that the stoma was the most practiced gesture before the appendectomy. The appendectomy is frequently performed in digestive surgery especially in appendicular peritonitis, acute appendicitis, appendicular abscess, but also in principle. Stomies are mostly performed in typhoidal ileal perforations. This is the preferred therapeutic attitude in Burkina Faso [15]. The constraints related to the wearing of an ostomy are accentuated in our context by the absence of stomatotherapist, the insufficiency of pockets for the equipment, and the delay of recovery of the digestive continuity often long. The quality of life of the person carrying the stoma is thus altered.

The morbidity of surgical acute abdomens was significant with $16 \%$ postoperative complications, dominated by parietal suppurations. Traoré [8] in Mali had $15.4 \%$ postoperative complications mainly due to surgical site infections. Surgical site infections, parietal and deep suppurations, are the main complications of surgical acute abdomens [5] [7]. The frequency of contaminated and dirty surgery in urgent digestive surgery, the inadequacy of hospital hygiene explain the importance of surgical site infections which prolong the length of stay and worsen the prognosis. Indeed, Assouto in Benin found that half of the operated patients who had a complication died [16]. 
Postoperative mortality was high at $8.7 \%$ with first-line generalized acute peritonitis. Harouna [2] had an even higher rate of $16.8 \%$ with acute intestinal occlusion as the leading cause of death. Our first cause of death was acute generalized peritonitis, which was also the most frequent pathology. Surgical acute abdomens require pre-, intra- and post-operative resuscitation. The delay in consultation, diagnosis, treatment observed in our context, alters the condition of the patients and increases the severity of the prognosis. Indeed, Harissou in Niger found that the delay in diagnosis and management had a statistically significant effect on prognosis [7]. We conducted a retrospective study on surgical emergencies operated on in the surgical ward of CHUSS. This study is limited by difficulties in analyzing data and obtaining some correlations between some clinical and pronostic variables. It permitted meanwhile to quantify the burden of the operated surgical emergencies. It's the first step on searching statistic correlations between clinical and pronostic variable, by conducting prospective studies.

\section{Conclusion}

Surgical acute abdomens are common with acute generalized peritonitis, acute intestinal occlusion and acute appendicitis. The postoperative morbidity rate is high and is mainly due to parietal suppurations. The high postoperative mortality could be reduced by early diagnosis and treatment, as well as better postoperative follow-up. This requires strengthening human and material resources, better organization, and an effective system of mutual social assistance.

\section{References}

[1] Mondor, H. (1947) Diagnostics Urgents: Abdomen. Masson, Paris.

[2] Harouna, Y., Ali, L., Seibou, A., Abdou, I., Gamatie, Y., Rakotomalala, J., et al. (2001) Deux ans de chirurgie digestive d'urgence à l'hôpital national de Niamey (Niger): Etude analytique et pronostique. Medecine d'Afrique Noire, 48, 49-54.

[3] Kotiso, B. and Abdurahman, Z. (2006) Pattern of Acute Abdomen in Adult Patients in Tikur Anbessa Teaching Hospital, Addis Ababa, Ethiopia. East and Central African Journal of Surgery, 12, 47-52.

[4] Choua, O., Ali, M.M., Kaboro, M., Moussa, K.M. and Anour, M. (2017) Etiological, Clinical, and Therapeutic Aspects of Acute Generalized Peritonitis in N'Djamena. Médecine et Santé Tropicales, 27, 270-273.

[5] Sima Zué, A., Josseaume, A., Ngaka Nsafu, D., et al. (2003) Les urgences chirurgicales au centre hospitalier de Libreville. Annales Françaises d'Anesthésie et de Réanimation, 22, 189-195. https://doi.org/10.1016/S0750-7658(03)00008-X

[6] Gaye, I., Leye, P.A., Traoré, M.M., et al. (2016) Prise en charge péri opératoire des urgences chirurgicales abdominales chez l'adulte au CHU Aristide Le Dantec. The Pan African Medical Journal, 24, 190. https://doi.org/10.11604/pamj.2016.24.190.9929

[7] Harissou, A., Ibrahim, A.M., Oumarou, H., et al. (2015) Retard diagnostique et implication pronostique en milieu africain: cas des urgences en chirurgie digestive à l'Hôpital national de Zinder, Niger. European Journal of Pharmaceutical Sciences, 
$11,251-262$.

[8] Traoré, A., Diakhaté, I., Dembelé, B.T., Togo, A., Kanté, L., et al. (2011) Complications postopératoires en chirurgie abdominale au CHU Gabriel Touré-Bamako, Mali. Medecine d'Afrique Noire, 58, 31-35.

[9] Soumah, S.A., Ba, P.A., Diallo-Owono, F.K. and Toure, C.T. (2011) Les abdomens aigus chirurgicaux en milieu africaIn: étude d'une série de 88 cas à l'hôpital Saint Jean de Dieu de Thiès. Bulletin medical d'Owendo (BMO), 13, 13-16.

[10] Ouangré, E., Zida, M., Bonkoungou, P.G., et al. (2014) Les péritonites aigües généralisées en milieu rural au Burkina Faso: à propos de 221 cas. Rev Cames Santé, 1, 75-79.

[11] Kambiré, J.L., Zaré, C., Sanou, B.G. and Kambou, T. (2017) Étiologies et pronostic des péritonites secondaires au centre hospitalier universitaire de Bobo-Dioulasso (Burkina Faso). Journal Aficain d' Hépato Gastroentéroogil, 1-3.

[12] Harouna, Y., Yaya, H., Abarchi, H., Rakoto Malala, J., Gazi, M., Seibou, A., et al. (2000) Les occlusions intestinales: Principales causes et morbi-mortalité à l'hôpital national de Niamey Niger: Etude prospective à propos de 124 cas. Médecine d'Afrique Noire, 47, 204-207.

[13] Ka Sall, B., Kane, O., Diouf, E. and Beye, M.D. (2002) Les urgences dans un centre hospitalier et universitaire en milieu tropical. Le point de vue de l'anesthésiste réanimateur. Medecine Tropicale, 62, 247-250.

[14] Rasamoelina, N., Rajaobelison, T., Ralahy, M.F., Riel, A.M., Rabarijaona, M., Solofomalala, G.D., et al. (2010) Facteurs de mortalité par les urgences digestives dans le service de réanimation du CHU de Fianarantsoa Madagascar. Revue Africaine d'Anesthésiologie et de médecine d'urgence, 2, 10-11.

[15] Zida, M., Ouédraogo, T., Bandré, E., Bonkoungou, G.P., Sanou, A. and Traoré, S.S. (2010) Iléostomie première des perforations iléales d'origine typhique: 62 cas à Ouagadougou (Burkina Faso). Medecine Tropicale, 70, 267-268.

[16] Assouto, P., Tchaou, B., Kangni, N., et al. (2009) Evolution post-opératoire précoce en chirurgie digestive en milieu tropical. Medecine Tropicale, 69, 477-479. 